\title{
Cognitive Information Processing in Borderline Personality Disorder: A Neuropsychiatric Hypothesis
}

\author{
J.Wesley Burgess, Ph.D., M.D. \\ Stanford University Medical Center, Stanford California
}

Follow this and additional works at: https://jdc.jefferson.edu/jeffjpsychiatry

Part of the Psychiatry Commons

Let us know how access to this document benefits you

\section{Recommended Citation \\ Burgess, Ph.D., M.D., J.Wesley (1990) "Cognitive Information Processing in Borderline Personality Disorder: A Neuropsychiatric Hypothesis," Jefferson Journal of Psychiatry. Vol. 8 : Iss. 2 , Article 7. DOI: https://doi.org/10.29046/JJP.008.2.004 Available at: https://jdc.jefferson.edu/jeffjpsychiatry/vol8/iss2/7}

This Article is brought to you for free and open access by the Jefferson Digital Commons. The Jefferson Digital Commons is a service of Thomas Jefferson University's Center for Teaching and Learning (CTL). The Commons is a showcase for Jefferson books and journals, peer-reviewed scholarly publications, unique historical collections from the University archives, and teaching tools. The Jefferson Digital Commons allows researchers and interested readers anywhere in the world to learn about and keep up to date with Jefferson scholarship. This article has been accepted for inclusion in Jefferson Journal of Psychiatry by an authorized administrator of the Jefferson Digital Commons. For more information, please contact: JeffersonDigitalCommons@jefferson.edu. 


\title{
Cognitive Information Processing in Borderline Personality Disorder: A Neuropsychiatric Hypothesis
}

\author{
J. Wesley Burgess, Ph.D., M.D.
}

\begin{abstract}
Neurocognitive information processing was compared in 18 borderline subjects and 14 controls of similar age and gender. An 11-item screening examination significantly differentiated the two groups $(P<0.001)$. Significant differences were found on Delayed Memory, Serial Sevens, Rhythm Reproduction, and Perseveration subtests $(\mathrm{P}<0.05)$. The results are interpreted as evidence for mild frontotemporal brain deficits. The findings support a developmental model of borderline disorder where early stress/injury during the childhood period of frontotemporal vulnerability results in failure to negotiate developmental landmarks and adult deficits in cognition, emotion/behavior modulation, and insight.
\end{abstract}

\section{INTRODUCTION}

Much of the contemporary interest in neurophysiological and neuropsychological information processing was influenced by the work of Luria $(1,2)$, who correlated aberrant patterns of thought and behavior with the location of specific brain lesions in hospitalized neuropsychiatric patients. The notion that the brain acts as a processor of exogenous information provides one theoretical framework to bridge biological, psychological and behavioral viewpoints of brain injury and mental illness $(1,2)$. Alterations in the processing of incoming sensory information are thought to play important roles in schizophrenia, mental retardation and learning disabilities (e.g., 3-17). However, the role of brain information processing in characterological disorders is unclear, and has received little clinical or research attention.

There are some suggestions of an organic component to characterologic disorders, particularly in borderline personality disorder, which could provide a substrate for altered neurocognitive processing. Adrulonis and colleagues $(18,19)$

The author thanks Drs. Brant Wenegrat and James Moses, Jr. for their helpful discussions. Support was provided by a Moos Fellowship in Psychiatry. Address correspondence to Dr. Burgess, Department of Psychiatry, Stanford University Medical Center, Stanford, California 94305. 
have found a disproportionate percentage of head trauma, encephalitis, epilepsy and learning disabilities in some subgroups including borderline disordered persons, suggesting they may have suffered lesions placing them at risk for neurocognitive dysfunctions.

There is also circumstantial evidence suggesting a role of organic dysfunction in the similarity between the symptoms of borderline personality disorder and the symptoms of acute, diffuse brain injury. The Diagnostic and Statistical Manual III-Revised (DSM-IIIR) lists the following symptoms of borderline personality disorder: chronic depression, mood instability, poor control of anger, relationship instability and impulsivity with impulsive sexual and violent acts (20). In patients with diffuse cortical injury secondary to closed head trauma, the most frequently reported behavioral symptoms include: chronic depression, mood instability, irritability with temper outbursts, and poor impulse control with sexual and aggressive acts (21-25). Obviously there is a strong convergence between the chronic symptoms of borderline personality disorder and the acute symptoms following adult frontal brain injury. Moreover, research studies and clinical impressions have associated characteriological disorders with parental deprivation and abuse (26); conditions which could result in possible early brain injury. Overall, this circumstantial evidence suggests that a theory of aberrant brain processing could explain aspects of characterologic behavioral dysfunction occurring after early neuropsychiatric trauma.

Studies of endogenously depressed patients have revealed deficiencies in standardized tests of cognition and information processing, including information coding, apprehension span, logical operations, and abstract functions (2734). These findings have been explained as a reversible impairment in cortical information processing accompanying affective changes (31). Although borderline personality disorder characteristically manifests marked affective changes, the demonstration of an equivalent neurocognitive deficit in borderline disorder is as yet unknown.

\section{Assumptions of Neurocognitive Testing}

The disciplines of neuropsychology/neuropsychiatry are concerned with the mechanisms and measurement of functional brain processes $(35,36)$. Typically, these include assessment of integrity of such brain functions as attention, memory, language, abstraction, and motor behavior (37). These general functional may be combined or separated into other derivative functional categories, depending on the theoretical stance of the author. Confirmation of localization site can come from anatomical measures such as imaging studies, physiological measures including EEG, evoked potentials or radioisotopic labeling metabolic studies. Importantly, certain neuropsychological subtests are thought to assess mental functions which localize more or less specifically to areas of the brain and can therefore be used as behavioral measures of organic or functional impairment (37). An outline of commonly presented mental functions, together with 
their associated brain mechanisms and subtests which are thought to localize to them is presented below.

Attention. The control of attention is intimately associated with corticoreticular, reticulocortical and thalamic projections and posterior internal capsule pathways, as well as other brainstem and midbrain structures (38-42). It can be measured by such subtests as Double Simultaneous Stimulation $(43,44)$, or vigilance subtests (37).

Memory. Recent memory is dependent on intact functioning of limbic system structures, particularly the bilateral hippocampus, dorsomedial thalamic nuclei, and mammalary bodies (45-48). Memory can be tested by repetition of digits $(4,10,14,49)$, delayed recall or free recall from a story $(2,37)$, or such batteries as the Wechsler Memory Scale (50).

Language. Functions of language are associated with temporal and parietotemporal cortical and subcortical language areas $(51,52)$. Classical dysfunctions include Broca's, Wernicke's, conduction, transcortical and subcortical aphasias (52). Expressive language functions are classically associated with anterior or Broca's area (53), whereas receptive language functions are classically associated with the posterior or Wernicke's area (54). Tests such as the Boston Naming Test (55), the FAS Controlled Oral Word Association Test (54), or the Animal Naming Test (56) particularly assess naming processes deficient in expressive aphasias.

Abstraction. Higher cognitive functions, including abstract operations, are associated with many areas of the brain, especially the parietal lobes (57-59). Operations of abstraction and generalization can be measured by standardized versions of the proverbs interpretation task $(37,61)$, the WAIS Similarities subscale (62), Raven Progressive Matrices (64), the Category Test (63), the nonverbal half of the Shipley Hartford Scale (60), and other tests.

Computations may be disrupted by dominant parietal lesions, as well as other lesions $(57,55,56)$. Arithmetic operations can be measured by the serial sevens task (37), the WAIS Arithmetic subscale (62), and other tasks.

Constructions. Constructions are nonverbal performance tasks relying on abstract, visuospatial and motor operations, which appear to overlap functions of abstraction and behavioral sequencing. These functions can be assessed by drawing to command, figure reproduction and copying tasks $(37,67,68)$. Unfortunately, the most widely used construction tests also include the additional confounding dimension of visuospatial memory, such as the Bender Visual Motor Gestalt (69,70), the Graham and Kendall Memory for Designs Test (71), and the Benton Visual Retention Test (67).

Behavioral Sequence. Organization of behaviors, and the ability to switch motor activities or mental sets is associated with the frontal cortex $(1,2,37)$. Perseveration errors are a hallmark of frontal damage (72), as are other errors in ordering. Behavioral sequencing is important in the execution of Luria's alternating movements task $(1,2)$, Luria's rhythm reproduction task $(1,2)$, Reitan's 
Trail Making Test (73), or the Proteus Maze Test (74). The Wisconsin Card Sorting Test (75), provides one measure of ability to switch mental sets without a strong loading for motor abilities.

Successive and Simultaneous Processing. Based on the work of Luria, Das and collegues (76) have taken another approach to functional localization, by proposing that certain tasks represent a specialization in "successive" information processing operations. According to Das (76) these include WAIS Digit Span and Digit Symbol subscales (62), free recall from a story (1,2,37), Reitan's Trail Making Test (73), and other tasks where information is presented in serial, sequential fashion. Impairment in successive processing tasks is generally associated with deficits of frontotemporal neocortical function (76). Conversely, other tasks involve more "simultaneous" information processing operations, including the Graham and Kendall Memory for Designs Test (71), the Raven Progressive Matrices (64), and the Bender Visual Motor Gestalt $(69,70)$. Impairment in these tasks is generally associated with deficits of parietoccipital neocortical function $(70,73,76)$.

\section{Research Hypothesis and Experimental Model}

We were impressed by the circumstantial evidence linking organic dysfunction and borderline personality disorder, and decided to test this relationship using the neuropsychiatric tools described above. As an initial step, we proposed a testable model of organic dysfunction leading to cognitive information processing defects in borderline personality disorder. This became the basis of a research hypothesis which was tested in a clinical population sample.

Developmental Model. We propose that certain developing brain areas, particularly frontal and temporal neocortex (which are at risk during early development (1) sustain injury during childhood trauma in persons who will later be diagnosed with borderline personality disorder. Although grossly focal neurological signs are absent, a chronic deficit in cognitive information processing localizing to the frontotemporal cortex remains. This early, generalized, subclinical insult results in difficulty negotiating developmental landmarks, with consequent personal and interpersonal problems during late childhood and adulthood. Initial behavioral deficits in childhood are partially compensated during personality development, but there remains a pattern of affective instability, relationship dysfunction, and impulsive thought and action in regard to both self and others. This pattern of behavioral impulsivity, emotional instability, and insight impairment may appear mild or severe, depending on the individual and the degree of stress in the environment.

Experimental Hypothesis. Based on the developmental model above, we hypothesize that a battery of neurocognitive screening tests will show measurably greater neurocognitive dysfunction in a sample population of individuals with borderline personality disorder than in a comparable population of individ- 
uals without this diagnosis. We would expect that the most deficient tests would localize to the frontal and temporal regions of the cortex.

\section{METHODS}

Subjects

Subjects were drawn from successive presentation for psychiatric evaluation, and neurocognitive function was tested in the overall context of comprehensive mental status evaluation. The borderline group was comprised of 18 patients with an independant diagnosis of borderline personality disorder by DSM-IIIR criteria from at least two clinicians. Subjects had no Axis I diagnosis, no history of neurological disorders, neurosurgery, or focal brain injury. All subjects denied the use of drugs for the week preceeding evaluation. In this group, mean age was 32.61 years $($ S.E. $=2.23)$, and gender was $33 \%$ female $(\mathrm{S} . \mathrm{E} .=12.1$; the high proportion of males reflects the overall hospital population).

The control group was comprised of 14 persons with no current history of psychiatric hospitalization, Axis I or II diagnosis, history of neurological disorders, neurosurgery, or focal brain injury. The average age was 31.36 years $(\mathrm{S} . \mathrm{E} .=1.21)$, and gender was $43 \%$ female $(\mathrm{S} . \mathrm{E} .=12.8)$.

\section{1-Item Screening Examination}

All patients were given an 11-question neurocognitive screening examination (see the Appendix), administered by the author, who was blind to the diagnosis of borderline personality disorder. Tests were drawn from the work cited above, particularly from the examination of Luria (1973). Two subtests were used to evaluate each of the functional categories of memory, language, abstract operations, and behavioral sequence, and three types of errors of order and sequencing were scored separately. Because all patients presented in a normal waking state of consciousness, no assessment of attention was provided. The entire examination required less than 10 minutes to administer and is therefore appropriate for clinical screening purposes. The examination is reproduced verbatim in the Appendix. The following outline describes the tests administered, and our understanding of the functions they measure.

\section{Memory}

1. Digit Span was the ability to repeat 6-7 digits in two presentations of 7 -digits each, adapted from WAIS Digit Span Subtest $(4,10,14,49,62)$.

2. Delayed Memory for 3 objects was the ability to repeat the 3 associated word pairs first presented in Question \#3 after 10 minutes of distraction; our version of this subtest in common use was adapted from Strub and Black (37). 


\section{Language}

3. Immediate Repetition was the ability to repeat the following 6 associated words after presentation at a rate of one per second: "red ball, blue car, city of Chicago" (51,77).

4. Object Naming was the ability to name common objects and their parts when presented visually: pen, cap, cover, clip, point, watch, band; $(37,77)$.

\section{Abstract Operations}

5. Serial Sevens tested the ability to serially subtract 7 from 100 five times with minimal help from the investigator $(57,65,66,78)$.

6. Proverb Interpretation tested the ability to interpret the proverb "Don't cry over spilt milk" abstractly, according to criteria adapted from Gorham $(37,61)$.

\section{Behavior Sequencing}

7. Luria Movements tested the ability to reproduce with either hand the following three sequential movements after seeing them performed by the investigator: clenched fist; outstretched palm \& fingers; thumb \& forefinger ring. This task was adapted from Luria $(1,2)$.

8. Rhythm Reproduction was the ability to reproduce with either hand the following three rhythms comprised of hard [T] and soft [ $\mathrm{t}]$ taps presented at one per second: TTTtttTTT; tttTTTttt; ttTTtt. This task was also adapted from Luria $(1,2)$.

\section{General Errors of Ordering and Sequencing}

9. Slowing Errors were scored when at least one response to a subtest was delayed for 4 seconds or more.

10. Perseveration Errors were scored when at least one response to a subtest was repeated more than once $(37,72)$.

11. Inversion Errors were scored when parts of at least one subtest response were reversed in order.

\section{Total Sum of Failed Subtests}

The total sum of failed subtests, ranging from 0-11 was recorded for all the subtests listed above.

\section{Statistical Analysis}

Group Comparisons. Neurocognitive measures from the borderline and control subject groups were compared using Multifactoral Analyses of Variance 
(MANOVA: 79,80). Statistical analysis was performed with the Statistical Analysis System (81). The MANOVA was a mixed design with the following model: [Diagnosis $\times$ (Measures $\times$ Subjects)], see Winer (82). The between subjects factor (Diagnosis) had 2 levels (Borderline Personality Disorder, Control). The within subjects factor (Measures) had 11 levels (Digit Span, Delayed Memory, Immediate Repetition, Object Naming, Serial Sevens, Proverb Interpretation, Luria Movements, Rhythm Reproduction, Slowing Errors, Perseveration Errors and Inversion Errors).

The MANOVA generated omnibus comparison (F-tests) for between subjects factors $(82,83)$ and multivariate tests (Hotelling Trace) with F-Test equivalents for within subjects factors $(79,80)$. Multiple comparisons testing allowed statistical comparisons to be made between the subject groups on specific subtests without violating Type I or Type II error assumptions by repeated individual tests. Multiple comparisons were made using Tukey's all-pairs test with appropriate error terms for a posteriori contrasts between borderline and control for each of the 11 subtests (84).

In addition to the above mixed, repeated measures design, one-factor analyses of variance (ANOVAs) were used to compare the subject groups for age and gender distribution. One-factor ANOVAs were also used to compare total sum of test performance between the subject groups $(82,83)$.

\section{RESULTS}

\section{Subject Groups}

The average age of the borderline and control subject groups was not significantly different, as shown by one-factor ANOVA [Age $\mathrm{F}(1,30)=0.22$; $\mathrm{P}=$ NS]. Similarly, gender distribution in the borderline and control subject groups was not significantly different [Gender $\mathrm{F}(1,30)=0.29 ; \mathrm{P}=\mathrm{NS}$ ]

\section{Neurocognitive Tests}

Omnibus Tests. Borderline and control groups showed a significant difference in performance across the 11 subtests of the neurocognitive screening examination [Diagnosis $\mathrm{F}(1,30)=14.180 ; \mathrm{P}=0.0007$ ]. Overall performance differed significantly according to subtest [Measures Hotelling Trace $=3.435$; $\mathrm{F}(10,21)=7.214 ; \mathrm{P}<0.0001]$, and an interaction comparison revealed that a significant component of this resulted from differential performance by the two subject groups across the 11 subtests [Measures $\times$ Diagnosis Hotelling Trace $=1.449 ; \mathrm{F}(10,21)=3.043 ; \mathrm{P}=0.015]$.

Multiple Comparisons. As shown in Table 1, multiple comparisons testing revealed significant impairment in the borderline group on subtests of Delayed Memory (Tukey test, $\mathrm{P}<0.05$ ), Serial Sevens (Tukey test, $\mathrm{P}<0.05$ ), Rhythm Reproduction (Tukey test, $\mathrm{P}<0.05$ ), and Perseveration Errors (Tukey test, 
TABLE 1.

Neurocognitive Screening Measures in 2 Groups $^{1}$

\begin{tabular}{|c|c|c|c|c|c|c|c|c|c|c|c|}
\hline \multirow{2}{*}{$\begin{array}{r}\text { Function }= \\
\text { TEST }=\end{array}$} & \multicolumn{2}{|c|}{ MEMORY } & \multicolumn{2}{|c|}{ LANGUAGE } & \multicolumn{2}{|c|}{ ABSTRACT } & \multicolumn{2}{|c|}{ BEHAVIOR } & \multicolumn{3}{|c|}{ GENERAL ERRORS } \\
\hline & $\underline{\text { SPAN }}$ & $\underline{\text { MEM3 }}$ & $\underline{\text { REPT }}$ & NAME & $\underline{\text { SER7 }}$ & $\underline{\text { PROV }}$ & $\underline{\text { LURI }}$ & $\underline{\text { RHTM }}$ & $\underline{\text { SLOW }}$ & $\underline{\text { PERS }}$ & INVT \\
\hline $\begin{array}{c}\text { BORDERLINE GROUP } \\
\% \text { Errors }= \\
\pm \text { S.E. }=\end{array}$ & $\begin{array}{l}5.6 \\
5.9\end{array}$ & $\begin{array}{l}36.1 \\
10.3\end{array}$ & $\begin{array}{l}0.0 \\
0.0\end{array}$ & $\begin{array}{r}16.7 \\
9.6\end{array}$ & $\begin{array}{l}55.6 \\
12.8\end{array}$ & $\begin{array}{l}5.6 \\
5.9\end{array}$ & $\begin{array}{l}61.1 \\
12.5\end{array}$ & $\begin{array}{l}77.8 \\
10.7\end{array}$ & $\begin{array}{l}50.0 \\
12.8\end{array}$ & $\begin{array}{l}27.8 \\
11.5\end{array}$ & $\begin{array}{l}50.0 \\
12.9\end{array}$ \\
\hline $\begin{array}{r}\text { CONTROL GROUP } \\
\% \text { Errors }= \\
\pm \text { S.E. }= \\
\text { SIGNIFICANCE }=\end{array}$ & $\begin{array}{r}0.0 \\
0.0 \\
- \\
\text { SPAN } \\
\end{array}$ & $\begin{array}{r}7.1 \\
6.7 \\
* * \\
\text { MEM3 } \\
\end{array}$ & $\begin{array}{r}7.1 \\
6.7 \\
\text { REPT } \\
\end{array}$ & $\begin{array}{r}0.0 \\
0.0 \\
- \\
\text { NAME }\end{array}$ & $\begin{array}{r}7.1 \\
6.7 \\
* * \\
\text { SER7 } \\
\end{array}$ & $\begin{array}{r}0.0 \\
0.0 \\
-\overline{P R O V} \\
\end{array}$ & $\begin{array}{c}28.6 \\
11.7 \\
- \\
\text { LURI } \\
\end{array}$ & $\begin{array}{r}35.7 \\
12.4 \\
* * \\
\text { RHTM } \\
\end{array}$ & $\begin{array}{c}35.7 \\
12.4 \\
- \\
\text { SLOW } \\
\end{array}$ & $\begin{array}{c}0.0 \\
0.0 \\
* * \\
\text { PERS } \\
\end{array}$ & $\begin{array}{c}35.7 \\
12.4 \\
\text { INVT }\end{array}$ \\
\hline
\end{tabular}

${ }^{1}$ Differences are significant at $\mathrm{P}<0.05$ by Tuken's multiple comparisons test, from MANOVA results. KEY: SPAN $=$ Digit Span, MEM3 = Delayed Memory, REPT = Immediate Repetition, NAME = Object Naming, SER7 = Serial Sevens, PROV = Proverb Interpretation, LURI = Luria Movements, RHTM = Rhythm Reproduction, SLOW = Slowing Errors, PERS $=$ Perseveration Errors, INVT $=$ Inversion Errors. 
$P<0.05)$. There was no significant difference between performance of the two groups on subtests of Digit Span, Immediate Repetition, Object Naming, Proverb Interpretation, Luria Movements, Slowing Errors, or Inversion Errors $(\mathrm{P}=\mathrm{NS})$.

\section{Total Sum of Failed Subtests}

Across the entire screening examination, the borderline group had an average of 3.86 errors (S.E. $=0.47$ ), whereas the control group had an average of 1.57 errors $(\mathrm{S} . \mathrm{E} .=2.22)$. This difference was significant, as described above for between subjects comparisons [Diagnosis $\mathrm{F}(1,30)=14.180 ; \mathrm{P}=0.0007$ ].

\section{DISCUSSION}

In summarizing the findings, it was shown that groups of borderline and control subjects of equivalent age and gender could be significantly discriminated by their performance on a screening neurocognitive examination. Deficits were most pronounced on subtests of Delayed Memory, Serial Sevens, Rhythm Reproduction, and Perseveration Errors.

\section{Implications of the Findings}

The finding that borderlines can be discriminated from controls by their performance on a screening neurocognitive examination provides evidence that that borderline thought processes differ from nonborderlines on a basic, measurable, neuropsychological level.

These findings support our research hypothesis that borderline individuals show a significant neurocognitive deficit. This hypothesis is based on a hypothetical developmental model, where stress, abuse or deprivation during vulnerable stages of early development result in chronic cognitive information processing errors. These errors impair the ability to negotiate formative developmental stages in childhood, and interfere with social/interpersonal relationships throughout adulthood, contributing to the characteristics diagnosed as borderline personality disorder (see Introduction).

\section{Interpretation of the Findings}

Contrary to our predictions, there was no concentration of deficits in a single functional category. Instead, poor performance was found in subtests measuring diverse functions of memory, abstract operations, behavioral sequencing and general errors of order and sequence, overlapping all neurocognitive functions except language. To find out the nature of the borderline dysfunction, we must look at the pattern of cognitive errors. 
The pattern of deficient subtests appear to best fit the Das (76) model of deficient sequential information processing, since deficits were found in subtests of Delayed Memory, Serial Sevens, Rhythm Reproduction, and Perseveration Errors, which all involve information that is presented in serial, sequential fashion, and where a string of stimuli must be sequentially memorized or manipulated. According to the model of Das and collegues (76), errors in sequential information processing suggest involvement of the frontotemporal pole. Unfortunately, we did not have a way of formally testing the significance of this relationship in our borderline population.

Another way of explaining the findings is to look for similarities between the deficient subtests of delayed memory, serial subtraction, rhythm reproduction and perseveration. All these tests require planning, multiple operations, and the maintainance of a prolonged response over time; thus, all the subtests are particularly subject to distraction or intrusion from exogenous or endogenous stimulation. This is similar to the pattern of errors which Teuber (58) associates with frontal brain injury, and is similar to the dimension of "planning" which Luria $(1,2)$ associates with frontal and prefrontal injuries.

Thus, the results of our study can be interpreted as supporting our hypothesis of mild injury to the frontal and temporal brain regions, which are particularly vulnerable during early childhood (1).

\section{Limitations of the Study}

The current methodology does not rule out effects of incidental variables like apathy, depression, anxiety or environmental stressors known to be common in borderline disordered persons lives. An explanation of our results based entirely on exogenous stressors cannot account for the magnitude of difference between borderline and control performance, nor can it explain how borderlines could perform well on such difficult subtests as Proverb Interpretation, while failing simpler tasks like Delayed Memory or Serial Sevens.

However, we suggest that future research employ tests for attentional/ motivational variables, if only to dispel the notion that subjects were inattentive or unmotivated. Although the 11-item screening examination is convenient to use, the use of additional tests for each neurocognitive function would provide a much stronger picture of neurocognitive deficits. Power of the examination would also be increased by exchanging the current pass/fail scoring system for an interval or continuous measurement scale (85). Additional tests with standardized, interval scoring are available $(1,2,37,62,70,73)$.

\section{CONCLUSIONS}

The present study is an attempt to provide a broader, multidisciplinary viewpoint on borderline personality disorder by evaluating cognitive information processing. The importance of the findings, which support a neurocognitive 
deficit in borderline frontotemporal processes, will depend on the results of future studies confirming and expanding the current results.

\section{REFERENCES}

1. Luria AR: The Working Brain. Basic Books, New York, 1973

2. Luria AR: Higher Cortical Functions in Man. Basic Books, New York, 1980

3. Starr AS: The diagnostic value of the audito-vocal digit span. Psychological Clinic $15: 61-84,1923$

4. Farnham-Diggory S: (Ed.) Information Processing in Children. Academic, New York 1972

5. Farnham-Diggory S: Development of logical operations and reasoning. In V Hamilton \& MD Vernon, eds. The Development of Cognitive Processes. Academic Press, New York, 1976

6. Russel EW: WAIS factor analysis with brain damaged subjects using criterion measures. Journal Consulting Clinical Psychology 32:133-139, 1972

7. Taub HA: A comparison of young, adult and old groups on various digit span tasks. Developmental Psychology 6:60-65, 1972

8. Rugel RP: WISC subtest scores of disabled readers. Journal Learning Disabilities $7: 57-64,1974$

9. McFie: 1975 Assessment of Organic Intellectual Impairment. Academic Press, New York, 1975

10. Chi MTH: Age differences in memory span. Journal Experimental Child Psychology 23:266-281, 1977

11. Hill AL: WAIS subtest score characteristics of institutionalized mentally retarded samples. Perceptual Motor Skills 47:131-134, 1978

12. Burgess JW: Development of social spacing in normal and mentally retarded children. Journal of Nonverbal Behavior 6:89-95, 1981

13. Burgess JW: The development of social group formation in normal and mentally retarded persons from early childhood through old age: Neuropsychiatric, developmental and cognitive implications. Psychiatry Research, 30:31-43, 1989

14. Dempster FN: Memory span. Psychological Bulletin 89:63-100, 1981

15. Asarnow RF \& MacCrimmon DJ: Attention/information processing, neuropsychological functioning and thought disorder during acute and partial recovery phases of schizophrenia. Psychiatry Research 7:309-319, 1982

16. Cowart CA and McCallum RS: Simultaneous-successive processing across the life span: A cross sectional examination of stability and proficiency. Experimental Aging Research 10:225-209, 1984

17. Burgess, JW and Fordyce WK: Effects of preschool environments on nonverbal social behavior: Toddlers' interpersonal distances to teachers and classmates change with environmental density, classroom design and parent-child interactions. Child Psychology Psychiatry 30:261-276, 1989

18. Andrulonis PA, Glueck BC, Stroebel CF, Vogel NG, Shapiro AL and Aldridge DM: Organic brain dysfunctions and the borderline syndrome. Psychiatric Clinics North America 4:47-66, 1981

19. Andrulonis PA, Glueck BC, et al.: Borderline personality subcategories. Journal of Nervous and Mental Disease. 170:670-679, 1982 
20. American Psychiatric Association. Diagnostic and Statistical Manual of Mental Disorders, Edition IIIR. American Psychiatric Association, Washington, DC, 1987

21. Oddy M, Humphrey M and Uttley D: Subjective improvement and social recovery after closed head injury. Journal of Neurology, Neurosurgery and Psychiatry 41:611616,1978

22. Levin HS, Grossman RG, Rose JE and Teasdale G: Long-term neuropsychological outcome of closed head injury. Journal of Neurology, Neurosurgery and Psychiatry 50:412-422, 1979

23. McKinley WW, Brooks DN, Bond MR, Martinage DP and Marshall MM: The short-term outcome of severe blunt head injury as reported by relatives of the injured person. Journal of Neurology, Neurosurgery and Psychiatry 44:527-533, 1981

24. Brooks DN and McKinley WW: Personality and behavioral change after severe blunt head injury - a relative's view. Journal of Neurology, Neurosurgery and Psychiatry 46:336-344, 1983

25. Thompsen IV: Evaluation and outcome of aphasia in patients with severe closed head injury. Journal of Neurology, Neurosurgery and Psychiatry 38:713-718, 1974

26. Millon $\mathrm{T}$ and Everly GS: Personality and Its Disorders: A Biosocial Learning Approach. Wiley Press, New York, 1985

27. Blatt SJ and Quinlan P: Punctual and procrastinating students. Journal Consulting Psychology 29:223-230, 1967

28. Glasser AJ and Zimmerman IL: Clinical Interpretation of the Wechsler Intelligence Scale for Children. Grune and Stratton, New York, 1967

29. Blatt SJ and Allison J: The inteligence test in personality assessment. In AI Rubin, ed. Projective Techniques in Personality Assessment. Springer, New York, 1968

30. Gilbert J: Clinical Psychological Tests in Psychiatric and Medical Practice. Thomas, Springfield IL, 1969

31. Donnelly EF, Waldman IN and Murphy DL et al.: Primary affective disorder: Thought disorder in depression. Journal of Abnormal Psychology 89:315-319, 1980

32. Brumback RA and Staton RD: Neuropsychological study of children during and after remission of endogenous depressive episodes. Perceptual Motor Skills 50:11631167,1980

33. McAllister TW: Cognitive functioning in the affective disorders. Comprehensive Psychiatry 22:572-586, 1981

34. McGee R, Anderson J, Williams S and Silva PA: Cognitive correlates of depressive symptoms in 11-year-old children. Journal of Abnormal Child Psychology 14:517524,1986

35. Grant I and Adams KM: Neuropsychological Assessment of Neuropsychiatric Disorders. Oxford University Press, New York, 1986

36. Kaplin HI and Sadock BJ: Comprehensive Textbook of Psychiatry. Williams and Wilkins, New York, 1990

37. Strub RL and Black FW: The Mental Status Examination in Neurology. Davis, Philadelphia, 1987

38. Magoun H: The Waking Brain. Thomas, Springfield, 1963

39. Watson RT et al.: Neglect after mesencephalic reticular formation lesions. Neurology 24:294, 1974

40. Watson RT et al.: Thalamic neglect. Archives of Neurology 38:501, 1981 
41. Mesulum MM: A cortical network for directed attention and unilateral neglect. Annuals of Neurology 10:309, 1981

42. Ferro J \& Kertesz A: Posterior internal capsule infarction associated with neglect. Archives Neurology 41:422, 1984

43. Williams D (Ed.): Modern Trends in Neurology, Vol 5. Appleton, New York, pp $1-28,1970$

44. Mutti M, Sterling HM and Spalding BV: Quick Neurological Screening Test Manual, Revised. Academic Therapy Publications, Novato CA, 1978

45. Milner B: Intellectual functions of the temporal lobes. Psychological Bulletin 51:42, 1954

46. Scoville W and Milner B: Loss of recent memory after bilateral hippocampal lesions. Journal Neurology Neurosurgery Psychiatry 20:11-21, 1957

47. DeJong $\mathrm{R}$, Itabashi $\mathrm{H}$ and Olson $\mathrm{J}$ : Memory loss due to hippocampal lesions. Archives Neurology 20:339, 1969

48. Victor M, Adams R and Collins G: The Wernicke Korsakoff Syndrome. Davis, Philadelphia, 1971

49. Black FW and Strub RL: Digit repetition performance in patients with focal brain damage. Cortex 14:12, 1978

50. Wechsler D: Wechsler Memory Scale. Psychological Corporation, New York, 1973

51. Geschwind N, Quadfasel F and Segarra J: Isolation of the speech area. Neuropsychologia $6: 327,1968$

52. Albert ML et al.: Clinical Aspects of Dysphasia. Springer Verlag, Vienna, 1981

53. Mohr JP: Broca's area and Broca's aphasia. In Whitaker $\mathrm{H}$ and Whitaker $\mathrm{H}$ (Eds): Studies in Neurolinguistics, Vol 1. Academic, New York, pp 201-235, 1976

54. Goodglass H and Kaplan E: The Assessment of Aphasia and Related Disorders. Lea \& Febiger, Philadelphia, 1983

55. Kaplan E, Goodglass $\mathrm{H}$ and Weintraub S: Boston Naming Test. Lea and Febiger, Philadelphia, 1983

56. Borowski JG, Benton AL and Spreen O: Word fluency and brain damage. Neuropsychologia 5:135, 1967

57. Critchley M: The Parietal Lobes. Edward Arnold, London, 1953

58. Teuber HL: The riddle of frontal lobe function in man. In Warren J and Akert $\mathrm{K}$ (Eds.): The Frontal Granular Cortex and Behavior. McGraw Hill, New York, pp 410-444, 1964

59. Black W: Cognitive deficits in patients with unilateral war-related frontal lobe lesions. Journal Clinical Psychology 32:366, 1976

60. Shipley WC: Institute of Living Scale. Western Psychological Services, Los Angeles, 1946

61. Gorham DR: The Proverbs Test. Psychological Test Specialists, Missoula Montana, 1956

62. Wechsler D: Wechsler Adult Intelligence Scale- Revised. Psychological Corporation, New York, 1981

63. Reitan R: A research program on the psychological effects of brain lesions in human beings. In Ellis N (Ed.): International Review of Research in Mental Retardation, Vol 1. Academic Press, New York, pp 153-218, 1966

64. Raven JC: Guide to the Standard Progressive Matrices. Psychological Corporation, New York, 1977 
65. Ferro JM and Botello MAS: Alexia for arithmetical signs: A cause of disturbed calculations. Cortex 16:175, 1980

66. Boller F and Grafman J: Acalculia: Historical development and current significance. Brain and Cognition 2:205, 1983

67. Benton AL: The Revised Visual Retention Test. Psychological Corporation, New York, 1974

68. Benton AL: Contributions to Neuropsychological Assessment. Oxford University Press, New York, 1983

69. Bender L: Bender Motor Gestalt Test. American Orthopsychiatric Association, New York, 1946

70. Golden CJ: Clinical Interpretation of Objective Psychological Tests. Grune and Stratton, New York, 1979

71. Graham FG and Kendall BS: Memory for Designs Test. Perceptual Motor Skills Suppliment 2-VIII 11:147-188, 1960

72. Stuss DT and Benson DF: Neuropsychological studies of the frontal lobes. Psychological Monographs 95:1, 1984

73. Reitan R: Investigation of the validity of Halstead's measures of biological intelligence. Archives of Neurology and Psychiatry 48:475, 1955

74. Porteus SD: Porteus Maze Test. Psychological Corporation, New York, 1965

75. Heaton RK: Wisconsin Card Sorting Test Manual. Psychological Assessment Resources, Odessa FL, 1981

76. Das JP, Kirby JR, and Jarman RF: Simultaneous and Successive Cognitive Processes. Academic Press, New York, 1979

77. Geschwind N: Disconnection syndromes in animals and man. II. Brain 88:585, 1965

78. Smith A: The serial sevens subtraction test. Archives Neurology 17:18, 1976

79. Bock RD: Multivariate Statistical Methods in Behavioral Research. McGraw Hill, New York, 1975

80. Morrison DF: Multivariate Statistical Methods. McGraw Hill, New York, 1976

81. SAS Institute, SAS/STAT Users Guide. SAS Institute, Cary NC, 1988

82. Winer BJ: Statistical principles in experimental design. McGraw Hill, New York, 1971

83. Snedecor GW and Cochran WG: Statistical Methods. McGraw Hill, New York, 1980

84. Games PA: A three-factor model encompassing many possible tests on independent groups. Psychological Bulletin 85:168-182, 1978

85. Siegel S: Nonparametric Statistics. McGraw, New York, 1956 


\section{APPENDIX}

\section{Cognitive Screening Test}

\section{MEMORY}

1. Digit Span: (Say at rate of one number per second. Record performance.)

"I'll say some numbers and you repeat them when I'm done."

“'3-2-6-0-9-1-0” (Record answers):

" 8-1-5-3-7-2-9" (Record answers):

SCORE: $\leq 5$ either trial, score 1

Score:

(Record slowing/hesitation, perseveration, inversion below.)

2. Verbal Delayed Memory: (See below).

\section{LANGUAGE}

3. Repetition: "I'll say three things and you repeat them when I'm done."

"A red ball, a blue car, and the city of Chicago."

"Now see if you can remember them when I ask you again later."

SC ORE: unless repetition is perfect, score 1

(Record slowing/hesitation, perseveration, inversion below.)

Score:

4. Naming: (Hold up item and point to part. Correct answers underlined.)

"What's this thing?" (point to pen; record answer):

"What's this thing?" (Point to cap/cover;

"What's this thing?" (Point to clip; record answer):

"What's this thing?" (Point to point/tip;

"What's this thing?" (Point to watch; record answer): record answer): record answer):

"What's this thing?" (Point to band; bracelet; record answer): SCORE: if any errors in naming, score 1

(Record slowing/hesitation, perseveration, inversion below.)

\section{ABSTRACTION}

5. Serial 7's: (Check if correct or record errors.)
"What's 100 minus 7?"
"And 7 from that?"
"Keep taking 7 away."

SCORE: if subject misses or unable to complete, score 1

Score:

(Record slowing/hesitation, perseveration, inversion below.)

6. Proverbs: (Record full answer).

"What does it mean to you when people say 'Don't cry over spilt milk?' "'

Score:

SCORE: use scoring key below; unless matches abstract, score 1

(Abstract: Don't worry about mistakes in the past. When something's gone, don't be concerned about it. What's done is done; don't brood. It's gone, don't worry. Don't cry when something goes wrong.

Concrete: Just clean it up. The milk's gone, you can't use it.)

(Record slowing/hesitation, perseveration, inversion below.)

\section{BEHAVIORAL SEQUENCE}

7. Luria Movements: "I'll do something with my hand and you try to repeat the same thing when I'm done."

(Tap your right knee 3 times with the right hand in these 3 positions):

FIST: (make a first and strike the knee with the heel of the hand)

PALM: (extend fingers out flat and strike the knee with the palm)

RING: (make 'OK' sign with the thumb and forefinger together in a ring; extend the other fingers and strike the knee with the heel of the hand) "Now you try it."

SCORE: if subject cannot reproduce in first trial, score 1

Score: (Record slowing/hesitation, perseveration, inversion below.) 


\section{APPENDIX (CONTINUED)}

\section{Cognitive Screening Test}

8. Rhythms Reproduction: 'I'll tap a little rhythm on my knee. Watch carefully and try to repeat it when I'm done."

(Tap on right knee with right hand in following sequence where $\left({ }^{*}\right)$ equals a brisk (1-sec) tap and (-) equals a slow (2-sec) tap):

*** _ _*** "Now you try." (Record response):

"Now try this one." (Tap out following sequence):

. . . *** . . . "Now you try." (Record response):

"Now try this one." (Tap out following sequence):

. . * . . "Now you try." (Record response:

SCORE: if subject misses or unable to complete, score 1

Score:

(Record slowing/hesitation, perseveration, inversion below.)

DELAYED MEMORY

2. Verbal Delayed Memory: (Record full answer).

"Now tell me the 3 things I asked you to remember earlier."

(Correct $=$ Red Ball, Blue Car, City of Chicago)

SCORE: if subject misses any or unable to complete, score 1

Score:

(Record slowing/hesitation, perseveration, inversion below.)

9. Slowing/Hesitation: ( $>3$ sec delay on any question. Record times:

SCORE: if subject hesitates on any question, score 1

Score:

10. Perseveration: (Repeats response on any question. Record times):

SCORE: if subject perseverates on any question, score 1

Score:

11. Inversion: (Inverts/reverses response on any question. Record times):

SCORE: if subject inverts on any question, score 1

Score:

TOTAL (add together all points from $0-11$ ) 